\title{
CFD simulation of liquid dispersion in bubble column
}

\begin{abstract}
In the current work, a modeling simulation based on the Computational Fluids Dynamic (CFD) method was done for two phase flow (gas-liquid) in two bubble columns. The effect of geometrical (two column diameters) and different gas velocity on the system hydrodynamics (gas hold up, mixing time) was investigated. Furthermore, the liquid circulation velocity in the columns was predicted. The simulated results were agreement with the experimental data reported in the literature. It was concluded that gas hold up was decreased while bubble column diameter increased from $15 \mathrm{~cm}$ to $30 \mathrm{~cm}$ in both experimental and CFD data's. But gas hold up was increased by increasing superficial gas velocity. In addition, it was seen that increasing of bubble column diameter from 15 to $30 \mathrm{~cm}$ leads to decreasing of mixing time. also mixing time reduced when superficial gas velocity was increased from 1 to $10 \mathrm{~cm} / \mathrm{s}$. Moreover, for more study on CFD simulation of bubble columns with different diameters, the effect of different superficial gas velocity on the liquid circulation velocity was predicted for two reactors. This prediction has shown increasing of liquid circulation velocity versus of increasing superficial gas velocity but it reduced when reactor diameter was increased.
\end{abstract}

Keywords: bubble column, superficial gas velocity, hold up, mixing time, liquid circulation velocity
Volume 2 Issue 3 - 2017

\section{E Bagheripour, S Moradi AR, Moghadassi SM, Hosseini M, Nemati F Amiri \\ Department of Chemical Engineering, Arak University, Iran}

Correspondence: E Bagheripour, Department of Chemical Engineering, Arak University, Iran,

Email bagheripoor_ehsan@yahoo.com

Received: October 24, 2016 | Published: April 21, 2017

\section{Introduction}

Bubble columns are contactors in which discontinues gas phase in the form of bubbles moves relative to a continues phase. The continues phase can be liquid or homogeneous slurry. ${ }^{1}$ Bubble columns serve as multiphase contactors and reactors in the chemical, petrochemical, biochemical, and metallurgical industries. As reactors, bubble columns are used for chemical processes involving oxidation, chlorination, alkylation, polymerization, and hydrogenation reactions. Other processes that employ bubble columns include hydro treating and conversion of petroleum residues and direct and indirect liquefaction in the production of liquid fuels from coal. ${ }^{2}$ This reactors offer many advantages such as simple construction, no mechanically moving parts, good heat and mass transfer properties, high thermal stability, good mixing, low power requirements and hence low construction and operating cost. ${ }^{3}$

Recently, many studies have been conducted on the hydrodynamics of gas- liquid flow, in bubble columns, in fluidized beds and in spouted beds. ${ }^{4-24}$

Gas holdup is defined as the fraction occupied by the gas phase in the total volume of a two- or three-phase mixture in a bubble column. It is one of the most important parameters characterizing bubble column hydrodynamics because it not only gives the volume fraction of the gas phase, it is also needed to estimate the interfacial area and thus the mass transfer rate between the gas and liquid phases. ${ }^{25}$

Good bubble column design requires knowledge of the effects of geometrical and operating parameters on hydrodynamics and mass transfer. Liquid circulation velocity and gas hold-up are the major hydrodynamic parameters and their knowledge is essential for a reliable description of a gas-liquid reactor. ${ }^{26}$
Reported studies indicate that the accurate and successful design and scale-up of bubble-column reactors requires an improved understanding of the multiphase fluid dynamics and its influence on phase holdup distribution, mixing, and transport characteristics. In recent years considerable effort has been done toward fundamental fluid-dynamic modeling of two-phase flows in bubble columns with the focusing of using these models as tools in the design of bubble column reactors. This has resulted in a many computational fluid dynamics (CFD) Studies. ${ }^{27-30}$

In this research, the effect of bubble column diameter and superficial gas velocity on the hydro- dynamics of bubble column was theoretically studied. For this aim, the Computational Fluid Dynamics (CFD) software (Comsol 3.5) was applied to obtain gas hold-up and mixing time. These data's were compared with the experimental data obtained from the literature. ${ }^{31}$ In addition for more study, a prediction of the effect of bubble column diameter and superficial gas velocity on the liquid circulation velocity on the column was done.

\section{Modeling}

In this work, a time-dependent simulation with no turbulence by selecting of axial symmetry (2D), Chemical Engineering Module $>$ Momentum Transport $>$ Multiphase Flow $>$ Bubbly Flow, Laminar $>$ Transient analysis in the model navigator of Comsol 3.5 software was used. The Bubbly flow application mode makes it easy to set up a multiphase flow model for gas bubbles rising through a liquid. It solves for the liquid velocity, the pressure, and the volume fraction of the gas phase.

\section{Continuity equation}

The continuity equation for each phase is as follow equation: 


$$
\frac{\partial\left(\tilde{\mathrm{n}}_{\mathrm{k}} \mathrm{a}_{\mathrm{k}}\right)}{\partial \mathrm{t}}+\nabla\left(\mathrm{a}_{\mathrm{k}} \tilde{\mathrm{n}}_{\mathrm{k}} \mathrm{u}_{\mathrm{k}}\right)=\mathrm{S}_{\mathrm{k}}
$$

Where, $\alpha, \rho$ and $u$ are gas hold-up, density and velocity in both gas and liquid phases, respectively. $\mathrm{K}$ and $\mathrm{S}_{\mathrm{k}}$ are phase type (for liquid phase: $\mathrm{k}=1$ and for gas phase: $\mathrm{k}=\mathrm{g}$ ) and source term of phase $\mathrm{k}$ in the domain, respectively.

\section{Momentum transfer equation}

The momentum transfer equation is derived as below expression:

$$
\frac{\partial\left(\alpha_{k} \rho_{k} u_{k}\right)}{\partial t}+\nabla\left(\alpha_{k} \rho_{k} u_{k} u_{k}\right)=-\alpha_{k} \nabla P+\alpha_{k} \rho_{k} g+\nabla \alpha_{k} \tau_{k} \pm F_{\text {int }}
$$

Where the right hand of the above equation demonstrate pressure difference (the first term), gravity force (the second term), stress (third term) and the ensemble averaged momentum exchange between the intra-phase force (fourth term). ${ }^{32,33}$

The equations of state for both gas and liquid phases are defined as following:

$$
\begin{aligned}
& \rho_{1}=\text { const } \\
& \rho_{g}=\frac{P}{R T_{0}}
\end{aligned}
$$

And

$$
\alpha_{l}+\alpha_{g}=1
$$

Where $\alpha_{l}$ and $\alpha_{g}$ represent liquid and gas volume fractions, respectively.

The quantity $F$ comes back to account the interaction forces (such as lift force, drag force and added mass force) between gas-liquid phases. ${ }^{34}$ The lift force, drag and turbulent stresses model supplied in the current work are described in the Moraveji et al. literature. ${ }^{35}$

\section{Simulation}

The experimental data was supplied from a published experimental literature work. ${ }^{31}$ For the purpose, two bubble columns with the same geometrical properties but different diameter of column (15 and $30 \mathrm{~cm}$ ) with different volumes containing of different superficial gas velocity were simulated by Comsol (version 3.5 a) as computational fluid dynamic instrument (CFD). The specification of these two bubble columns was shown in Table 1.

Table I Liquid-physical properties and selected operating conditions. ${ }^{31}$

\begin{tabular}{ll}
\hline Ug (Air), $\mathrm{cm} / \mathrm{s}$ & $\mathrm{I}-10$ \\
Pressure $=\mathrm{atm}$ & $\mathrm{I}$ \\
Liquid mode & Batch \\
Distilled water & $\mathrm{L}=1 \mathrm{~g} / \mathrm{cm}^{3}, \quad \mu \mathrm{L}=10^{-4} \mathrm{~g} / \mathrm{cm} . \mathrm{s}, \quad \sigma \mathrm{L}=72 \mathrm{dyn} / \mathrm{cm}$ \\
Temperature ${ }^{\circ} \mathrm{C}$ & 20 \\
Initial Liquid height, & 130 \\
Ho cm
\end{tabular}

In this simulation, two phases were employed were air and water as gas and liquid phases respectively. The liquid phase height before gas sparging was fixed $1.3 \mathrm{~m}$ for both reactors in all experiments. In this situation, the gas volume fraction was equal to 0 before sparging gas in liquid.

The simulation of both columns became steady state after various times ( 5 to $23 \mathrm{~s}$ for different column diameter and different superficial gas velocity). According to the simulation, mesh consists of 4224 and 9984 elements respectively for column with $15 \mathrm{~cm}$ and $30 \mathrm{~cm}$ diameter. For slip model, the pressure drag balance with large bubbles was supplied. For inlet and outlet, the boundary condition was the gas flux and the gas outlet, respectively. The liquid phase was as primary phase and the gas phase was as dispersed phase.

Figure 1 shows meshes generation for the bubble column with diameter of $15 \mathrm{~cm}$. Figure 2 shows the distribution of gas through the water from $0 \mathrm{~s}$ to reaching steady state after 16 seconds at superficial gas velocity of $(\mathrm{Ug}) 7 \mathrm{~cm} / \mathrm{s}$. These fig (Figure 2 ) shows that after passing time from 16 second, the volume fraction of gas in this column has became steady and increasing of time from 16 to 30 seconds has not resulted any changes in volume fraction of gas.

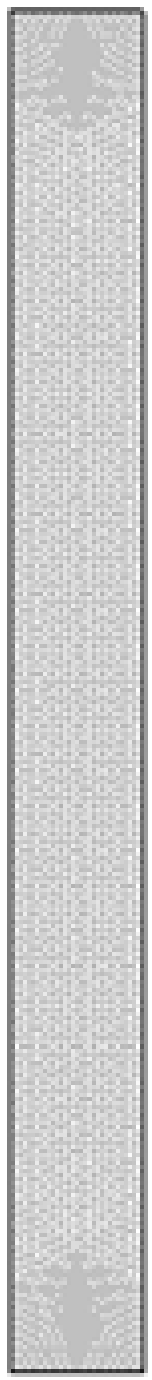

Figure I Meshes generation for the bubble column with diameter of $15 \mathrm{~cm}$. 

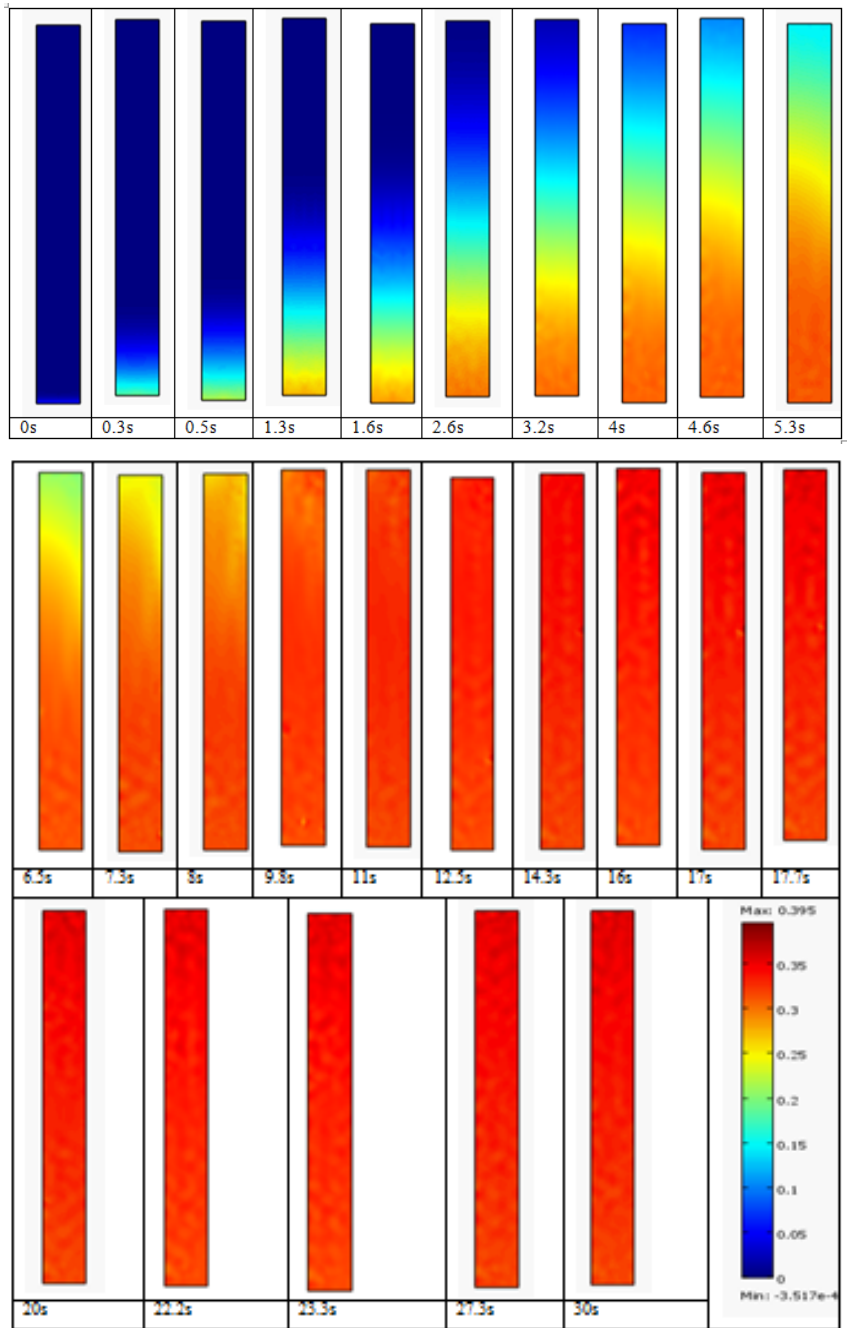

Figure 2 Volume fraction of air with aeration of $V=7 \mathrm{~cm} / \mathrm{s}$ in the reactor with $15 \mathrm{~cm}$ diameter at different times.

\section{Results and discussion}

The effect of superficial gas velocity and column diameter on the gas hold up

The two reactors with different column diameters $(15$ and $30 \mathrm{~cm})$ with similar geometry were simulated at $20^{\circ} \mathrm{C}$ under atmospheric pressure. The superficial gas velocity-hold up relation of the gas phase is the most important design parameter for two phase (gas-liquid) bubble column reactors for anticipating of heat and mass transfer coefficients and studies on hydrodynamic parameters. Gas hold up is an important parameter, because it estimates the amount of the gas phase reminded in the system at any time.

Figures 3, Figure 4 show the effect of superficial gas velocity on the volume fraction of gas (gas hold up) for both reactor scale ( 15 and $30 \mathrm{~cm}$ diameter) respectively. In these figs the experimental data ${ }^{31}$ and CFD results were compared. As shown in both figs, the gas hold up has increased by increasing the superficial gas velocity in two columns. In the Figure 3, gas hold up has increased from 0.0263 to 0.215 for CFD results and from 0.03 to 0.18 for experimental while superficial gas velocity $(\mathrm{Ug})$ has increased from 1 to $10 \mathrm{~cm} / \mathrm{s}$ in the reactor with $15 \mathrm{~cm}$ diameter. As it can be seen, the resulted data's carried out of the CFD simulation are very similar to the experimental data's and have good agreement together.

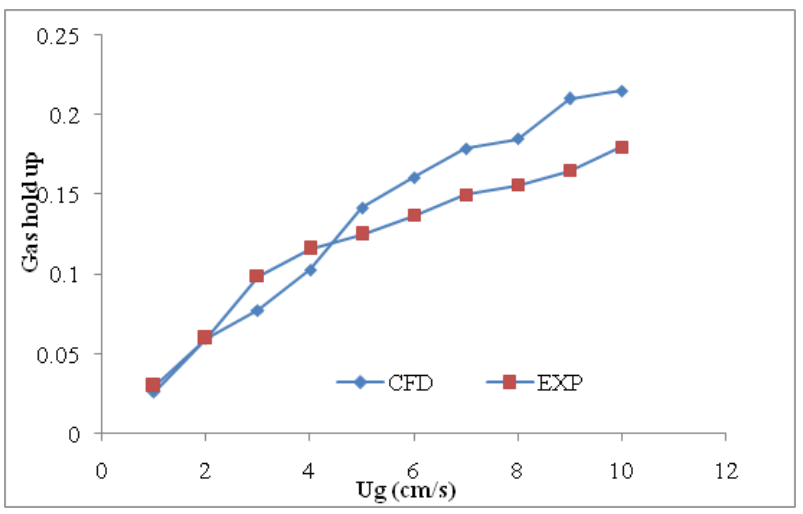

Figure 3 Comparison between the experimental data and CFD results for gas hold up in the reactor with $15 \mathrm{~cm}$ diameter versus superficial air velocity $(\cup g)$.

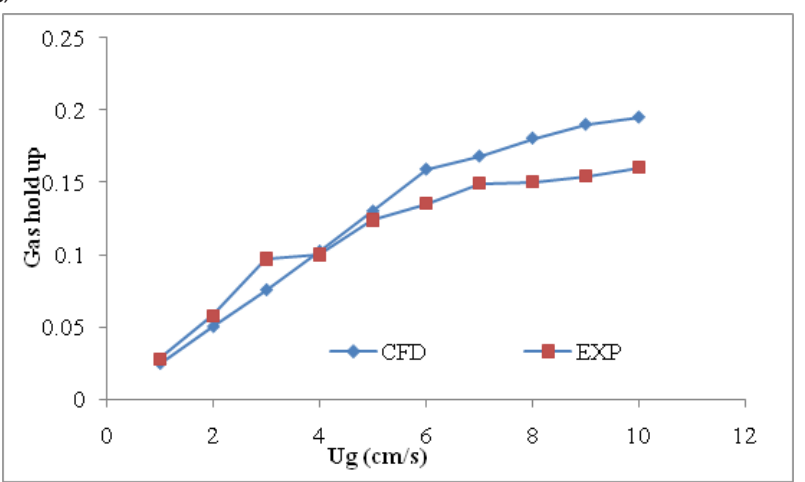

Figure 4 Comparison between the experimental data and CFD results for gas hold up in the reactor with $30 \mathrm{~cm}$ diameter versus superficial air velocity $(\mathrm{Ug})$.

In addition in the Figure 4, the value of gas hold up has increased from 0.0245 to 0.195 for CFD and from 0.028 to 0.16 for experimental data's in the column with $30 \mathrm{~cm}$ diameter. These results have a similar trend and good agreement together too.

Also the comprised results between experimental and CFD was briefly shown in Table 2 .

Table 2 Experimental and CFD simulation results for both 15 and 30 reactor diameters

\begin{tabular}{lllllll}
\hline Ug $(\mathbf{c m} / \mathbf{s})$ & D=I5cm & \multicolumn{5}{c}{ D=30cm } \\
\cline { 2 - 7 } & EXP & CFD & Err\% & EXP & CFD & Err\% \\
\hline 1 & 0.03 & 0.02 & 33.3 & 0.02 & 0.02 & 0 \\
2 & 0.06 & 0.06 & 0 & 0.05 & 0.05 & 0 \\
3 & 0.09 & 0.07 & 22.2 & 0.09 & 0.07 & 22.2 \\
4 & 0.11 & 0.1 & 9 & 0.1 & 0.1 & 0 \\
5 & 0.12 & 0.14 & 16.6 & 0.12 & 0.13 & 8.3 \\
6 & 0.13 & 0.16 & 23 & 0.13 & 0.15 & 15.3 \\
7 & 0.15 & 0.17 & 13.3 & 0.14 & 0.16 & 14.2 \\
8 & 0.15 & 0.18 & 20 & 0.15 & 0.18 & 20 \\
9 & 0.16 & 0.21 & 31.2 & 0.15 & 0.19 & 26.6 \\
10 & 0.18 & 0.21 & 16.6 & 0.16 & 0.19 & 18.7 \\
\hline
\end{tabular}


Figure 5 shows the comparison of gas hold up in both reactor with diameters of 15 and $30 \mathrm{~cm}$ versus of different superficial gas velocity. As it can be seen in this fig, the gas holdup is found to reduce with increasing column diameter. The reduction of gas hold up by increasing of reactor diameter is more sensible in higher superficial gas velocity especially in $\mathrm{Ug}=10 \mathrm{~cm} / \mathrm{s}$. This behavior of gas holdup is due to increase in liquid circulation with increasing column diameter, due to these strong circulations, the bubble will be accelerated and reduction in gas holdup occurred. There are the same results in the literatures. ${ }^{36-38}$

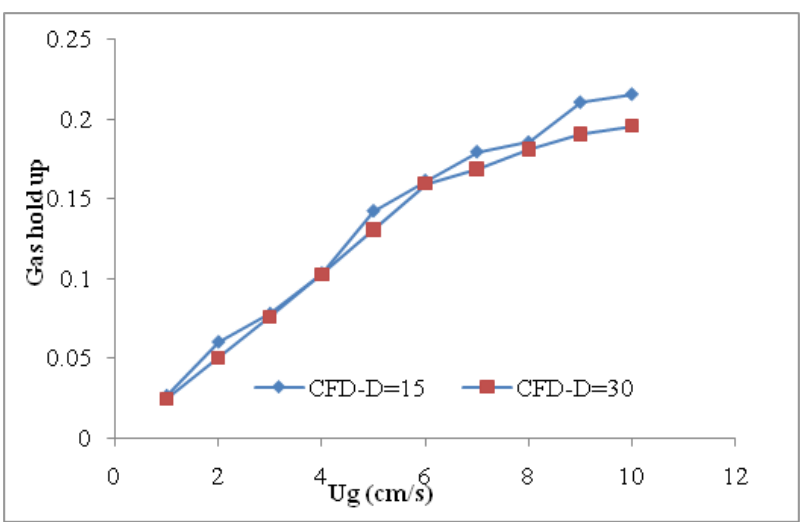

Figure 5 The effect of bubble column reactor diameter on the gas hold up (CFD results).

\section{Effect of superficial gas velocity and column diameter on mixing time}

Mixing time is a direct indicator of the mixing capacity of a reactor. For measuring of mixing time, time of running increased for each reactor during simulation at different superficial gas velocity to reach the steady state condition. In this case increasing of more time has no effect on the volume fraction of air in the column. This time has expressed as mixing time. It means in this time the reactors have homogenous condition. The results of mixing time for both CFD simulation and experimental has reported in Figures 6, Figure 7 for reactors with 15 and $30 \mathrm{~cm}$ diameter respectively versus of different superficial gas velocity. As it is obvious, in these two reactors, mixing time values have reduced by increasing of superficial gas velocity dispersed in the columns. As shown in these two figures, there is a falling trend between increasing of superficial gas velocity and mixing time. In another word, it can be resulted from these two figs, that increasing of superficial gas velocity in the bubble columns leads to reducing of mixing time. This can be attributed to the average liquid circulation velocity (VC), which enhances with increase in Ug. ${ }^{31}$ The resulted of CFD simulation and experimental have a very good agreement as it is clearly seen in the Figures 6, Figure 7.

Figure 8 shows the effect of column diameter on mixing time. As it is clearly seen, the mixing time decreases with increasing of bubble column diameter from 15 to $30 \mathrm{~cm}$. this phenomenon is may be due to increasing of liquid circulation velocity with the increase in column diameter. $^{3}$

\section{Prediction of liquid circulation velocity in term of su- perficial gas velocity}

After comparison of the CFD results and experimental data in previous sections for gas hold up and mixing time, it was found a very good agreement between CFD and experimental data. It was conclud- ed that the CFD is a very useful and accurate tool for scaling-up and prediction as well. Thus in this section for more study on this type of reactors, a prediction of liquid circulation velocity was done by CFD.

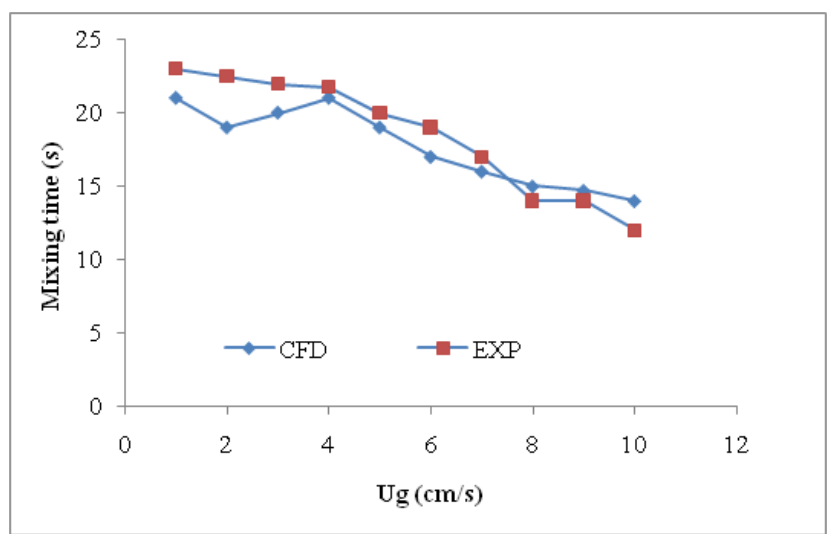

Figure 6 Comparison between the experimental data and CFD results for mixing time in the reactor with $15 \mathrm{~cm}$ diameter versus superficial air velocity (Ug).

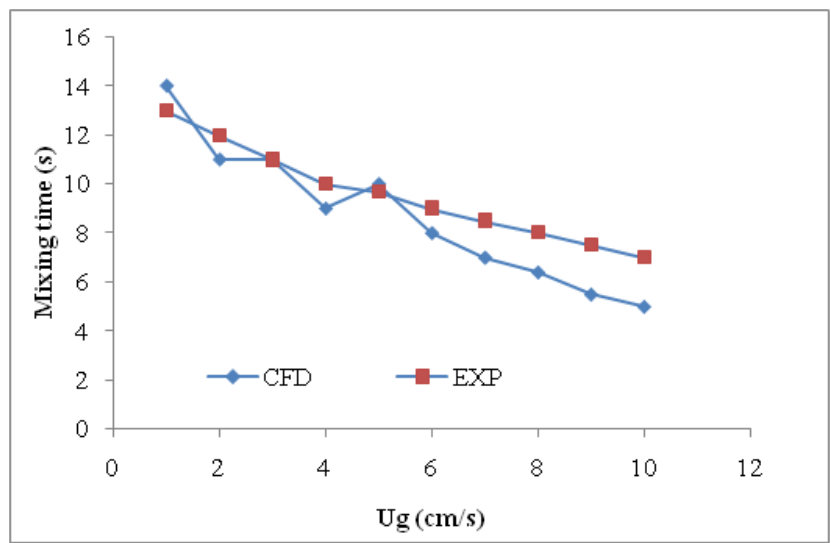

Figure 7 Comparison between the experimental data and CFD results for mixing time in the reactor with $30 \mathrm{~cm}$ diameter versus superficial air velocity $(U g)$.

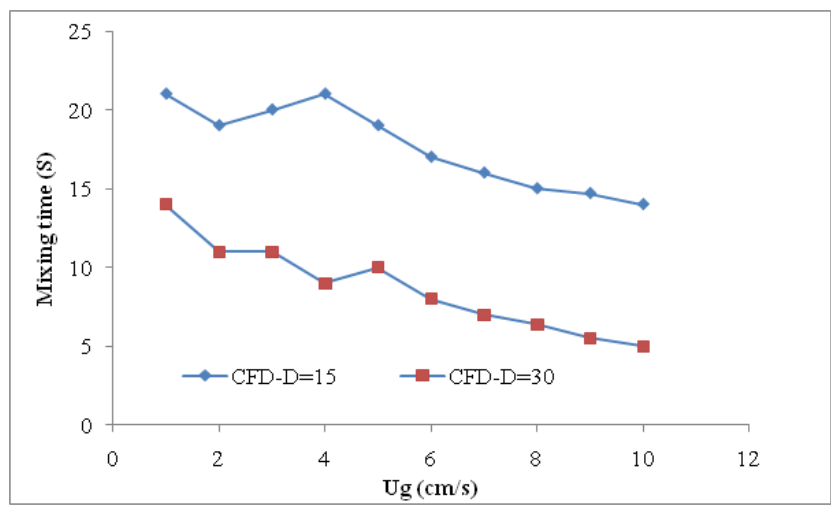

Figure 8 The effect of bubble column diameter on the mixing time (CFD results).

The results for this prediction were shown in the Figure 9. It can be obviously concluded that while liquid circulation velocity $(\mathrm{Vc})$ is low, the mixing time is high as it can be seen in the Figure 9. It means due to the relatively lower (VC) values than a lower energy is available for the liquid motion, which causes an increase in mixing time. 


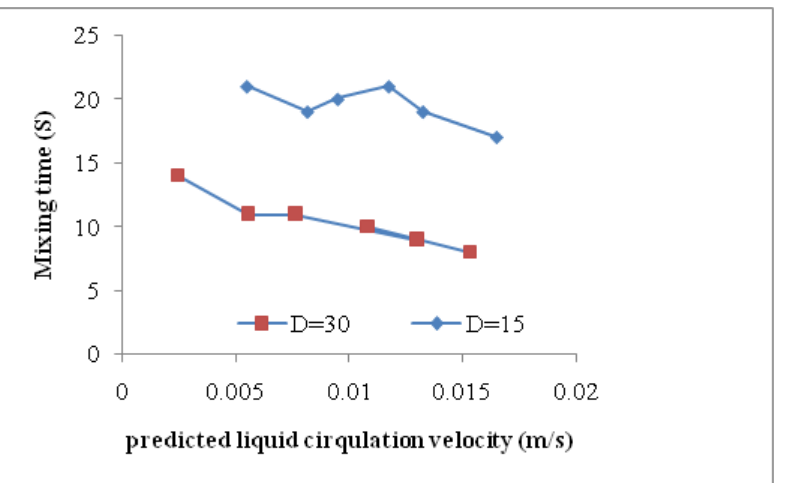

Figure 9 The relation between mixing time and predicted liquid circulation velocity.

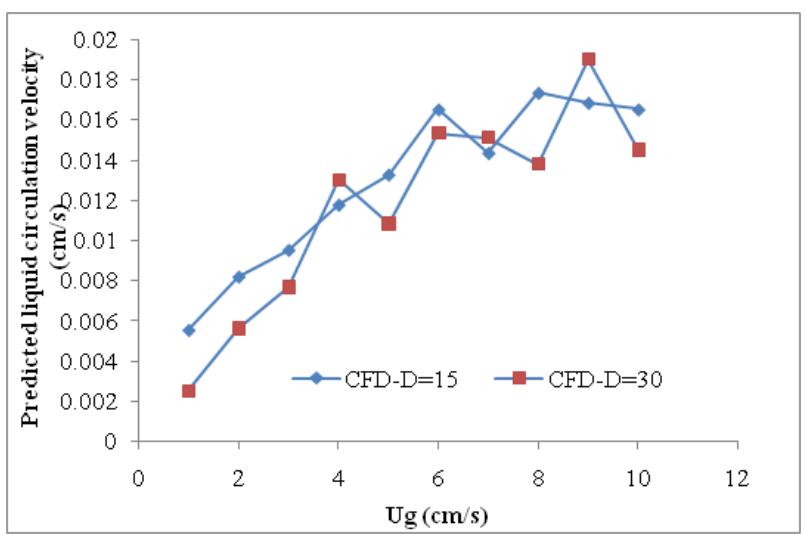

Figure 10 Prediction of liquid circulation velocity versus different superficial gas velocity.

The results of comparison between predicted liquid circulation velocity for two reactors (15 and $30 \mathrm{~cm}$ diameter) versus of superficial gas velocity have came in the Figure 10. As shown in this fig, liquid circulation velocity approximately has increased by increasing the superficial gas velocity, although some deviations were observed for the reactor with diameter of $15 \mathrm{~cm}$ (in the $\mathrm{Ug}=7,9$ and $10 \mathrm{~cm} / \mathrm{s}$ ) and for the reactor with $30 \mathrm{~cm}$ as diameter (in the $U \mathrm{~g}=5,8$ and $10 \mathrm{~cm} / \mathrm{s}$ ). In the most of points, the simulated results followed the ascendant trends. There are the same results in the published literature. ${ }^{39}$

\section{Conclusion}

In this study, gas-liquid phase bubble column with the two various diameters were simulated by means of CFD instrument. The gas phase and liquid phase was air and water respectively. The effect of superficial gas velocity and reactor diameter on the some hydrodynamic parameters such as gas hold up and mixing time was investigated. The CFD results were supported by published experimental work. The results showed that the gas holdup is directly related to superficial gas velocity. It increased linearly with increasing of superficial gas velocity. But when reactor diameter was increased from 15 to 30 $\mathrm{cm}$, gas hold up reduced. In addition it was resulted that increasing of superficial gas velocity and reactor diameter leads to decreasing of mixing time during the simulation and experimental. Moreover, a prediction was done for the effect of superficial gas velocity on the liquid circulation velocity. It was concluded that increasing of superficial gas velocity, leads to increasing overall liquid circulation velocity.
It should be mentioned, the simulated results were in a very good agreement with the experimental results. Thus it was concluded that the CFD is a very useful instrument and accurate tool for scaling-up and prediction as well.

\section{Acknowledgements}

None.

\section{Conflict of interest}

The author declares no conflict of interest.

\section{References}

1. Shah YT, Kelkar BG, Godbole SP. Design parameter estimation for bubble column reactors. AIChE Journal. 1982;28(3):353-379.

2. S Degaleesan, M Dudukovic, Y Pan. Experimental Study of Gas-Induced Liquid-Flow Structures in Bubble Columns. AIChE Journal September. 2001;47(9):1913-1931.

3. Bouchaib G, Christophe V, Abdel Hafid E, et al. Identification of Flow Regimes and Transition Points in a Bubble Column through Analysis of Differential Pressure Signal Influence of the Coalescence Behavior of the Liquid Phase. Chem Eng and Proc. 2006;45:214-223.

4. K Akita, F Yoshida. Gas holdup and volumetric mass transfer coefficient in bubble columns. Ind Eng Chem Proc Des Dev. 1973;12:76-80.

5. R Botton, D Cosserat, JC Charpentier. Influence of column diameter and high gas throughputs on the operation of a bubble column. Chem Eng J. 1978;16:107.

6. SP Godbole, MF Honath, YT Shah. Holdup structure in highly viscous Newtonian and non-Newtonian liquids in bubble columns. Chem Eng Commun. 1982;16(1-6):119-134.

7. YT Shah, BG Kelker, SP Godbole, et al. Design parameters estimations for bubble column reactors. AIChE J. 1982;28(3):353-379.

8. H Hikita, S Asai, K Tanigawa, et al. Gas holdup in bubble columns. Chem Eng J. 1980;20:59-67.

9. H Hikita, H Kikukawa (1974) Liquid phase mixing in bubble columns. $J$ Chem Eng Jpn. 1974;8:191.

10. S Wachi, H Morikawa, K Ueyama. Gas holdup and axial dispersion in gas-liquid on current bubble column. J Chem Eng Jpn. 1987;20:309 p.

11. A Yamashita. Effect of liquid depth, column inclination and baffle plates on gas holdup in bubble columns. J Chem Eng Jpn. 1985;18(4):349 p.

12. SP Godbole, A Schumpe, YT Shah, et al. Hydrodynamics and mass transfer in non-Newtonian solutions in a bubble column. AIChE J. $1984 ; 30(2): 213-220$

13. A Mersmann. Design and scale-up of bubble and spray columns. Ger Chem Eng. 1978;1:1.

14. JR Grace, CJ Lim. Permanent jet formation in beds of particulate solids. Can J Chem Eng. 1987;65(1):160-162.

15. WC Yang, DL Keairns. AICHE Symp Series 176. 1978;74:218-225.

16. M Nishikawa, Y Yonezawa, T Kayama, et al. Studies on gas holdup in gas-liquid spouted vessel. J Chem Eng Jpn. 1976;9(3):214-219.

17. M Nishikawa, K Shiino, T Kayama, et al. Gas absorption in a multi-stage gas-liquid spouted vessel. J Chem Eng Jpn. 1985;18(6):496-501.

18. MZ Anabtawi, BZ Uysal, RY Jumah, et al. Gas holdup in a bi-dimensional two phase spouted bed. Chem Eng J. 1991;47:135-139. 
19. MZ Anabtawi, BZ Uysal. Gas holdup in a bi-dimensional three phase spouted bed. Chem Eng J. 1992;50:143-147.

20. MZ Anabtawi, GA Ibrahim. Gas holdup and volumetric liquidphase mass transfer coefficient in a spout-fluid bed. J Chem Eng Jpn. $1995 ; 29: 20-24$

21. MZ Anabtawi. Gas holdup in highly viscous liquids in gas- liquid spouted beds. J Chem Eng Jpn. 1996;28(6):684-688.

22. MZ Anabtawi, GA Ibrahim, MBW Nabhan. Gas holdup and axial dispersion coefficient in gas-liquid concurrent spout-fluid beds. $J$ Sep Sci Technol. 1996;31(14):1893-1905.

23. T Kurda, AS Mujumdar, GSV Raghavan. Gas-to-particle heat transfer in two dimensional spouted beds. Int Commun Heat Mass Transfer. 1989;16:731 p.

24. KB Mathur, N Epstein. Spouted Beds. USA: Academic Press; 1974

25. Shah YT, Kelkar BG, Godbole SP. Design parameter estimation for bubble column reactors. AIChE Journal. 1982;28(3):353-379.

26. M Blažej, M Kiša, J Markoš. Scale Influence on the Hydrodynamics of an Internal Loop Airlift Reactor. Chemical Engineering and Processing. 2004;43(12):1519-1527.

27. Svendsen HF, HA Jakobsen, R Torvik. Local Flow Structures in Interna Loop and Bubble Column Reactors. Chem Eng Sci. 1992;45:2325.

28. Grienberger $\mathrm{J}, \mathrm{H}$ Hofmann. Investigations and Modeling of Bubble Columns. Chem Eng Sci. 1992;47:2215.

29. Joshi JB, VV Ranade, SD Gharat, et al. Sparged Loop Reactors. Can J Chem Eng. 1990;68:705.

30. Sokolichin A, G Eigenberger. Gas-Liquid Flow in Bubble Columns and Loop Reactors:Part 1. Detailed Modelling Numerical Simulation. Chem Eng Sci. 1994;24:5735.
31. Hayder Abd Al kaream Muhsin, Mohammad Fadhil Abid. Experimental study of liquid dispersion in bubble column. Diyala Journal of Engineering Sciences. 2008;1(1):56-85.

32. IM Šijački, RR Čolović, D Lj Petrović, et al. Diluted Alcohol Solutions in Bubble Columns and Draft Tube Airlift Reactors with a Single Orifice Sparger:Experiments and Simple Correlations. Journal Chemical Technology and Biotechnology. 2010;85(1):39-49.

33. B Albijanić, V Havran, D Lj Petrović, et al. Hydrodynamics and Mass Transfer in a Draft Tube Airlift Reactor with Dilute Alcohol Solutions. AIChE Journal. 2007;53(11):2897-2904.

34. MK Moraveji, B Sajjadi, M Jafarkhani, et al. Experimental Investigation and CFD Simulation of Turbulence Effect on Hydrodynamic and Mass Transfer in a Packed Bed Airlift Internal Loop Reactor. International Communications in Heat and Mass Transfer. 2011;38(4):518-524.

35. MK Moraveji, E Ghaderi, R Davarnejad. Effective Parameters Consideration in Ohmic Heating Process in Two Phase Static System of Bio-Particle-Liquid. International Journal of Food Engineering. 2011;7(1):1-17.

36. Krishna R, Urseanu MI, Van Baten JM, et al. Influence of Scale on the Hydrodynamics of Bubble Columns Operating in the ChurnTurbulent Regime:Experiments vs. Eulerian Simulations. Chem Eng Sci. 1999;54:4903-4911.

37. Krishna R, JM van Baten, MI Urseanu. Scale effects on the hydrodynamics of bubble columns operating in the homogeneous flow regime. Chem Eng Technol. 2001;24(5):451-458.

38. Akita K, Yoshida F. Gas holdup and volumetric mass transfer coefficient in bubble columns. Ind Eng Chem Process Des Dev. 1973;112:76-80.

39. Reza Davarnejad, Ehsan Bagheripoor, Abolfazl Sahraei. CFD Simulation of Scale Influence on the Hydrodynamics of an Internal Loop Airlift Reactor. Engineering. 2012;4(10):668-674. 